\title{
TINJAUAN POSMODERNISME: LIBERALISASI CHARTERED ACCOUNTANT DARI BELENGGU KAPITALISME
}

\author{
Retna Safriliana, Universitas Merdeka Malang \\ Email: retna.safriliana@unmer.ac.id
}

\begin{abstract}
ABSTRAK
Artikel ini bertujuan untuk memberikan pencerahan pandangan posmoderisme dalam profesi akuntan di Indonesia dalam kolonialisme barat. Chartered Accountant sebagai profesi akuntan di Indonesia menjadi korban kapitalisme di Asia Tenggara, pemberlakuan Masyarakat Ekonomi ASEAN (MEA) menjadi tantangan bagi akuntan di Indonesia. Profesi akuntan yang merupakan jasa profesi, mempunyai persaingan yang sangat ketat di Negara Asia Tenggara. Lahirnya IAI Kompartemen Akuntansi Syariah menjadi awal liberalisme dalam melawan kolonialisme akuntansi barat, karena akuntansi yang diterapkan di Indonesia yang mayoritas muslim menjadi titik terang dunia akuntansi. Diharapkan IAI Kompartemen Aksyar dapat menjadikan Indonesia mempunyai kemampuan memperbaiki kondisi akuntansi di Indonesia.
\end{abstract}

Kata Kunci: Posmodernisme, Liberalisasi, Chartered Accountant, Kapitalisme

\section{PENDAHULUAN}

Memasuki abad 21 perkembangan profesi akuntan menjadi perhatian dunia pendidikan, praktisi dan masyarakat Indonesia. Profesi yang menjadi obyek kekuasaan politik, dan profesi yang mudah diperdagangkan. Jitpaisanwattana, Pathumcharoenwattana, \& Tantawutho, (2015) menyatakan bahwa pemberlakuan Masyarakat Ekonomi ASEAN (MEA) menjadi serangan yang harus diperhitungkan oleh profesi akuntan, karena kebutuhan akuntan di Indonesia sangat besar tetapi jumlah akuntan hanya 24.587 akuntan yang tercatat sebagai anggota IAI. Jumlah akuntan menurut Dewo (2016), masih di bawah Singapore sebanyak 28.891 akuntan, Malaysia sebanyak 31.815 akuntan dan Thailand sebanyak 62.739 akuntan. Jasa Akuntansi saat ini, tidak hanya membuat laporan keuangan saja tetapi akuntansi dapat memberikan konsultasi di bidang perpajakan dan sistem akuntansi. Hal ini yang menjadikan akuntan merupakan profesi yang sangat berkembang dan banyak dibutuhkan oleh entitas bisnis, sehingga akuntan menjadi pilihan profesi yang menjanjikan dalam dunia kerja. MEA merupakan kesepakatan yang dibuat antar negara-negara ASEAN agar terjadi transaksi ekonomi. Kesepakatan ini dinamakan Mutual Recognation Agreement (MRA), dimana harapan pemberlakuan MEA di wilayah ASEAN akan terjadi pasar terbuka atau pasar bebas di bidang investasi, barang, jasa, dan tenaga kerja. Hal ini yang menjadi ancaman bagi bangsa Indonesia, jika tidak mempersiapkan profesi akuntan yang kompetitif dengan 
negara lain (Upa, 2015). MRA menyepakati adanya pembebasan terhadap batasanbatasan yang menghalangi rekrutmen tenaga kerja asing, sehingga tenaga kerja asing dapat masuk di wilayah ASEAN sesuai dengan kemampuannya. Rerangka MRA dalam kesepakatan pembebasan tenaga kerja di wilayah ASEAN dalam jasa profesi diantaranya: 1) Jasa arsitek, 2) Jasa teknik, 3) Jasa perawatan, 4) Praktisi medis, 5) Praktisi gigi/ dokter gigi, 6) Jasa akuntan, dan 7) Jasa surveyor (Keliat, et al, 2013)

Perkembangan akuntan profesional di Indonesia yang selama ini diatur oleh Ikatan Akuntan Indonesia dibawah pengawasan Federation Accounting Standard Board (FASB). Saat ini berubah dalam International Fedetaion of Accounting (IFAC), mau tidak mau Indonesia harus dapat mengikuti aturan yang dibuat oleh IFAC untuk menyesuaikan dalam bidang Akuntansi, Auditing dan Pendidikan. IAI sebagai organisasi profesi yang mengikuti perkembangan standar yang diharuskan IFAC, telah melakukan adopsi penuh terhadap standar keuangan internasional (International Financial Reporting Standard/IFRS), di bidang auditing telah memberlakukan standar auditing internasional (International Standard on Auditing-ISA), dan bidang Pendidikan Akuntansi telah disiapkan kurikulum Program Strata 1 standar pendidikan akuntansi internasional (International Education Standard-IES). Globalisasi menuntut penyetaraan semua bidang dan profesi antar negara, sehingga tidak ada gap standar masing-masing negara. Hal ini yang menjadi tantangan bagi profesi akuntan di Indonesia dalam mempersiapkan persaingan profesi akuntan. Alasan penyetaraan, harmonisasi maupun globalisasi menjadi alasan yang digunakan untuk merubah aturan dan standar akuntansi maupun profesi akuntan yang ada di Indonesia. Chartered Accountant (CA) sebuah sebutan untuk Akuntan Profesional, menjadi bahan baku untuk mendapatkan keuntungan atas sebuah gelar baru. Kebutuhan sertifikasi atau keprofesionalisme di bidang akuntansi menjadi bahan untuk menguras sebuah aktualisasi diri manusia.

Adanya realitas sosial yang mempunyai kekuasaan dalam memperangkap individu dalam masyarakat ke dalam jaringan tertentu menjadi hal yang penting untuk diperhatikan. Diantaranya adalah, 1) Realitas sosial tentang penjajahan profesi akuntansi di Indonesia dari kolonialisme organisasi profesi internasional 2) Bagaimana peran akuntan dalam upaya menghadapi dan tindakan atas realitas sosial tersebut. Realitas sosial yang berkaitan dengan profesi akuntan inilah yang menjadi titik perhatian dalam artikel ini, bahwa profesi akuntan yang selama ini ada di Indonesia dengan cepat mengalami perubahan karena kepentingan politik atau kekuasaan bangsa.

Artikel ini mengkaji secara kritis terhadap realitas sosial yang dihadapi akuntan di Indonesia tentang liberalisasi (pembebasan) profesi akuntan dalam kapitalisme organisasi profesi, ditinjau dari pandangan posmodernisme. Tujuan artikel ini adalah: 1) Memberikan wawasan tentang pandangan posmodernisme yang merupakan kebalikan dan melampui (beyond) pandangan modernisme (mainstream). 2) Memberikan wawasan yang lebih luas dalam memandang fenomena sosial yang berkaitan dengan penjajahan 
profesi akuntan di Indonesia. 2) Memberikan pandangan kritis tentang bagaimana membebaskan belenggu penjajahan (kolonialisme) profesi akuntan.

\section{TINJAUAN PUSTAKA}

\section{Posmodernisme}

Pandangan posmodernisme tentang Chartered Accountant merupakan fenomenafenomena sosial yang terbentuk melalui proses praktik akuntansi dan bisnis dengan cara "keluar" dari "perangkap logosentrisme" realitas sosial yang ada, untuk memberikan arah pembentukan realitas sosial yang lebih baik. Dan memberikan pandangan kritis tentang kesadaran etis (ethical consciousness) dan peran akuntan dalam keterlibatan aktif akuntan dalam profesionalisme realitas sosial. Posmodernisme pada dasarnya adalah sebuah worldview yang mencoba meletakkan diri "di luar" paradigma modern. Artinya bahwa ia menilai modernisme bukan dari kriteria modernitas, tetapi melihatnya dengan cara kontemplasi dan dekonstruksi" (Hadiwinata, 1994). Posmodernisme bukan suatu pandangan yang homogen yang berbeda dengan pemikiran modernisme yang mempunyai sistematika terstruktur dan formal. Posmodernisme merupkan pemikiran yang mengandung keaneka-ragaman pemikiran "yang meliputi marxisme barat, strukturalisme francis, nihilisme, etnometodogi, romantisme, populisme, dan hermeneutika" (Hadiwinata 1994). Mungkin karena adanya keberagaman inilah akhirnya posmodernisme tidak mempunyai "bentuk" yang jelas. Tetapi "tidak berbentuknya" posmodernisme ini justru merupakan "bentuk" asli dari dirinya. Pemikiran ini muncul karena modernisme mempunyai ketidakberesan dalam kehidupan manusia. Modernisme menciptakan penyebaran hegemoni peradaban barat, industrialisasi, urbanisasi, teknologi dan konsumerisme. Modernisme juga menimbulkan adanya rasisme, perbedaan kaya dan miskin, diskriminasi, pengangguran dan stagnasi. Dalam pemikiran posmodernisme, modernisme merupakan simbol atau logosentrisme dalam dunia akuntansi.

Logosentrisme dalam akuntansi menetapkan bahwa standar dan praktik akuntansi harus berlaku secara internasional. Hal ini dapat dilihat dalam praktik penerapan standar akuntansi internasional atau harmonization of accounting penerapan International Financial Reporting Standard (IFRS). Menurut pandangan posmodernisme, penerapan ini merupakan penindasan atau kolonialisme akuntansi di Indonesia, atau "kesewenangan" yang memarginalkan praktik-praktik atau nilai-nilai lokal (sebuah negara, misalnya) yang mungkin sangat sesuai dengan kondisi dan konteks kelokalan negara atau masyarakat yang bersangkutan. Demikian juga dalam bidang profesi akuntan, yang menjadi obyek perubahan kebijakan barat demi kepentingan dunia (= dan negara barat). Kekuasaan ini semakin terlihat dengan adanya keharusan untuk mengikuti IFRS dengan alasan globalisasi. Pandangan posmodernisme menyebut ini sebagai kolonialisme.

Akuntansi telah mengalami perubahan yang sangat pesat seiring dengan perkembangan pengaruh lingkungan organisasi, struktur, teknologi, konflik sosial dalam 
organisasi (Hopwood, 1987). Fakta ini menunjukkan bahwa faktor kultur masyarakat, sistem ekonomi, sistem politik dan sistem sosial yang bersifat lokal, dapat membentuk praktik akuntansi yang menunjukkan culturasi tertentu.

Posmodernisme menentang semua logosentris harmonization of accounting, yang merupakan hegemoni logosentris. Foucault telah melakukan pemberontakan terhadap hegemoni logosentris, yang mengesampingkan "sang lain/ the other", pada posisi marginal, terlupakan dan bahkan terhinakan. Artinya, ada bentuk-bentuk ilmu pengetahuan yang tertindas, demi menjaga wacana yang sedang berkuasa secara fungsional dan sistematis. Foucault menyatakan, pembebasan ilmu pengetahuan yang tertindas hanya dapat dilakukan melalui kritik, yaitu wacana yang menempatkan ilmu pengetahuan yang tidak ilmiah pada posisi sebagai wacana yang layak. Kritik ini oleh Foucault dinamakan "genealogi", yang mempunyai misi perjuangan melawan wacanawacana global dan universal yang saat ini menjadi kekuatan yang sedang berkuasa (Foucault 1980). Genealogi ini sebagai suatu proses sejarah yang tidak linear. Artinya, terbentuknya realitas sosial sebenarnya tidak melalui proses linier tetapi melalui proses yang polivalen dan "acak" yang menuntun kepada tujuan yang benar-benar belum diketahui secara pasti. Genealogi memberikan fleksibilitas dan kebebasan dalam melihat realitas sosial yang terbentuk dalam suatu masyarakat, yang berbeda dengan pandangan modernisme (positivism) Foucault (1987). Dalam realitas sosial juga terdapat hubungan timbal balik antara ilmu pengetahuan dan kekuasaan (Foucault 1980). Posmodernisme juga mengakui adanya "kemajemukan" dengan menempatkan "sang lain" pada relasi yang bersifat terbuka, demokratis, kooperatif, humanis, dan terdesentralisasi ke dalam wacana yang semula didominasi dan dikuasai oleh logosentrisme golongan elite semacam konglomerat, kapitalis, dan penguasa. Posmodernisme menolak adanya penunggalan dan mengakui adanya kemajemukan, dan mengakui adanya Power dan Knowledge, dikatakan bahwa kuasa adalah pengetahuan dan pengetahuan itu sendiri adalah kuasa. Kapitalisme sebagai pengetahuan dengan kuasa yang kuat mampu membentuk, pola pikir seorang individu menjadi pola pikir yang kapitalis. Posmodernisme menentang pandangan modernisme dengan cara kontemplasi dan dekonstruksi. Kontemplasi berarti melakukan pemikiran rasional yang melibatkan hati nurani. Sedangkan dekonstruksi merupakan suatu pemikiran modernisme yang memasukkan "yang lain" dalam pandangan modernisme. Koonhof (1999) menyatakan Posmodernisme sebagai cermin dalam mengembangkan modernisme, bahwa perkembangan akuntansi telah membukakan pandangan untuk mempertimbangkan realitas sosial. Posmodernisme dapat dikembangkan dalam implikasi akuntansi dan profesi akuntansi sebagai modifikasi modernisme.

\section{HASIL DAN PEMBAHASAN}




\section{Perkembangan Profesi Akuntan Di Indonesia}

Perkembangan profesi Akuntan di Indonesia dapat dijelaskan dalam tiga masa, yaitu masa lama, masa orde baru, dan masa reformasi.

Masa Orde Lama. Profesi akuntan lahir sejak jaman Belanda, karena kebutuhan dalam praktik pembukuan atau akuntansi. Tahun 1747 akuntansi sudah dipraktikkan dengan sistem pembukuan berpasangan atau double entry bookkeeping seperti yang dikembangkan Luca Pacioli. Pada masa ini akuntan sangat dibutuhkan karena kegiatan perekonomian Belanda mengalami peningkatan. Adanya peningkatan perekonomian ini dituntut untuk melakukan pencatatan pembukuan yang baik dan dapat dipertanggungjawabkan. Tahun 1907 kebutuhan tenaga auditor juga diperlukan untuk melakukan pekerjaan audit (Upa, 2015). Akuntan Indonesia mulai dipertimbangkan sebagai profesi penting dalam pembukuan dan pencatatan keuangan yang dapat dipercaya oleh semua pihak, menjadi pemikiran untuk pengakuan profesi akuntan. Tahun 1947 hanya ada satu orang akuntan di Indonesia yaitu Prof. Dr. Abutari. Pemerintah Indonesia menetapkan Undang Undang No.34 tahun 1954 yang mengatur tentang profesi akuntan dan penetapan gelar akuntan. Pemerintah Indonesia memberikan keistimewaan kepada Perguruan Tinggi Negeri yang mempunyai Jurusan Akuntansi saat itu, mahasiswa lulusannya dapat memperoleh gelar akuntan secara otomatis. Perguruan Tinggi yang membuka jurusan Akuntansi yaitu Universitas Indonesia 1952, Universitas Padjajaran 1961, Universitas Airlangga 1962, Universitas Gadjahmada 1964, Universitas Sumatra Utara 1967 dan Institut Ilmu Keuangan (1967) atau Sekolah Tinggi Akuntansi Negara (STAN) 1974. Perkembangan Akuntansi di beberapa perguruan tinggi tersebut mengalami pergeseran dari pembukuan dengan sistem pembukuan Belanda menuju sistem akuntansi Amerika. Kebutuhan tenaga akuntan semakin meningkat karena semua perusahaan membutuhkan pembukuan yang cermat dan dapat dipertanggungjawabkan. Profesi yang dapat diandalkan adalah akuntan, menjadikan minat mahasiswa untuk mengambil jurusan akuntansi meningkat, tetapi perlu pengelolaan mutu lulusan yang berkualitas dan dapat diandalkan. Tanggal 23 Desember 1957 Mahasiswa lulusan Universitas Indonesia dan beberapa akuntan senior terdorong mendirikan Organisasi Profesi Akuntan atau Ikatan Akuntan Indonesia (IAI) dengan ketua Umum pertama Prof. Soemardjo Tjitrosidojo seorang akademisi berpendidikan Belanda.

Masa Orde Baru. Tahun 1969 untuk pertama kalinya IAI menyelenggarakan Konvensi Akuntansi, dengan pembahasan Surat Keputusan Menteri Keuangan yang mewajibkan akuntan bersertifikat menjadi anggota IAI. Untuk perguruan tinggi yang mempunyai jurusan akuntansi tetapi tidak diakui oleh pemerintah, apabila lulusannya menginginkan gelar Akuntan diwajibkan mengikuti Ujian Negara Akuntan (UNA) yang terdiri dari UNA Dasar dan UNA profesi. Tahun 1973 IAI membentuk Komite Norma Pemeriksaan Akuntan (KNPA) untuk mendukung terciptaya perbaikan ujian akuntansi. tahun 1974 didirikan Yayasan Pengembangan Ilmu Akuntansi Indonesia (YPAI), dan 
tahun 1985 dibentuk Tim Koordinasi Pengembangan Akuntansi (TKPA) untuk mengembangkan pendidikan akuntansi, profesi akuntan dan kode etik profesi. Tahun 1990-an kegiatan-kegiatan IAI selalu didanai Bank Dunia, ini yang menjadikan IAI sebagai organisasi yang berproyek. IAI (2015) terdapat empat kompartemen sesuai bidang keahlian akuntan yaitu: IAI Kompartemen Akuntan Publik (IAI KAP), IAI Kompartemen Akuntan Pendidik (IAI KAPd), IAI Kompartemen Akuntan Manajemen (IAI KAM), IAI Kompartemen Akuntan Sektor Publik (IAI KASP).

Masa Reformasi. Pada masa reformasi setelah tahun 1998 Bank Dunia mempunyai banyak peranan dalam profesi akuntan. Tahun 2007 dalam Kongres Luar Biasa (KLB) memutuskan bahwa Anggota IAI dapat menjadi anggota organisasi profesi perseorangan dan asosiasi. IAI KAP berubah format menjadi Asosiasi Akuntan Publik dengan nama Institut Akuntan Publik Indonesia (IAPI) dan anggotanya ditetapkan sebagai anggota asosiasi IAI. demikian juga IAI KAM berubah format menjadi Asosiasi Akuntan Manajamen dengan nama Institut Akuntan Manajemen Indonesia (IAMI). Organsasi profesi Akuntan di Indonesia yang saat ini diakui adalah Ikatan Akuntan Indonesia (IAI). Profesi akuntan di Indonesia adalah semua bidang pekerjaan yang mempergunakan keahlian akuntansi, termasuk pekerjaan akuntan publik, akuntan intern, akuntan pemerintah dan akuntan pendidik. Perkembangan profesi akuntan saat ini belum signifikan, karena kebutuhan tenaga akuntan dan jumlah akuntan yang tersedia belum seimbang. Tahun 2015, Jumlah akuntan di Indonesia yang terdaftar di IAI sebanyak 24.587, sedangkan jumlah unit bisnis mencapai 66.000. Jumlah lulusan Akuntansi setiap tahun 35.000 orang dengan akuntan pendidik sebanyak 6.654 orang (Dewo, 2014). Melihat data tersebut menunjukkan bahwa, minat lulusan mahasiswa akuntansi pada bidang pekerjaan akuntansi sangat rendah. Hal ini menjadi keprihatinan dunia pendidikan, karena di satu sisi negara membutuhkan tenaga akuntan, tetapi di sisi lain sumber daya manusia yang diharapkan dapat memenuhi kebutuhan tenaga akuntan sangat kecil. Tahun 2012 terjadi serangan terhadap akuntan di Indonesia dengan diberlakukannya IAI sebagai anggota International Federation of Accounting (IFAC) sebagai organisasi profesi akuntan se-dunia. Keberadaan IFAC ini mengharuskan Indonesia untuk mengikuti standar dan aturan yang ditetapkan oleh IFAC.

\section{Liberalisasi Profesi Akuntan}

Liberalisasi merupakan sebuah pembebasan terhadap belenggu yang terjadi, demikian pula yang terjadi dalam profesi akuntan. Pembebasan terhadap belenggu kapitalisme barat, menjadi tantangan bagi Indonesia untuk kepentingan bangsa. Batasan suatu negara menjadi batasan juga bagi tenaga kerja profesional, dimana antar negara memiliki aturan dalam ketenagakerjaan. Pemberlakuan MEA merupakan kunci kebebasan dalam memilih tenaga kerja profesional antar negara, sehingga tenaga kerja asing-pun juga dapat memasuki Indonesia untuk bekerja sesuai dengan profesinya. Jasa 
Akuntansi merupakan bagian arus bebas jasa dan profesi Akuntansi yang menjadi bagian dari tujuh arus bebas profesi, untuk perkembangan ekspansi bisnis. Keliat, et.al (2013) menyatakan bahwa liberalisasi perdagangan terbatas pada perdagangan barang dan jasa. Tahun 1970 liberalisasi mulai berkembang di sektor jasa, yang 75\% dikuasai oleh negara maju. Oleh karena itu diatur oleh World Trade Organization (WTO) membentuk General Agreement on Trade in Services (GATS) yang mengatur liberalisasi perdagangan sektor jasa, dalam implementasi liberalisasi sektor jasa tingkat regional maupun internasional. Mengacu pada GATS tersebut, tahun 1992 ASEAN mengeluarkan perjanjian ASEAN Free Trade Area (AFTA). Perjanjian ini belum berjalan maksimal, dikarenakan adanya krisis ekonomi yang ada di Asia Tenggara. Setelah krisis ekonomi teratasi, perkembangan ekonomi mulai tampak dengan munculnya kekuatan perdagangan China dan India, yang melemahkan ekonomi ASEAN. Oleh karena itu, tahun 2015 Negara-negara ASEAN membentuk ASEAN Economics Community-AEC atau Masyarakat Ekonomi ASEAN (MEA) yang merupakan integrasi ekonomi regional. Agenda MEA di semua anggota ASEAN untuk menjadikan: 1) Pasar dan basis produksi tunggal, 2) Kawasan ekonomi yang kompetitif, 3) Wilayah pengembangan ekonomi yang merata dan 4) Daerah sepenuhnya terintegrasi ke dalam ekonomi global. Konsep ini yang selanjutnya menjadikan hubungan antar negara ASEAN sebagai pasar tunggal dan dasar produksi tunggal meliputi area perdagangan bebas, penghilangan tarif perdagangan antar negara ASEAN, pasar tenaga kerja dan modal yang bebas, serta kemudahan arus keluar masuk prosedur antar negara ASEAN.

Perkembangan profesi akuntan tahun 2010-an telah berkembang dengan adanya tuntutan kompetensi di bidang keahlian akuntan. Munculnya proyek IAI dengan menyelenggarakan sertifikasi menjadi ajang proyek dan prestisme gelar selain gelar akuntan. Menjamurnya Lembaga Sertifikasi Profesi dari Badan Nasional Sertifikasi Profesi (BNSP) menjadi kerancuan dan kebingungan masyarakat menyikapi kondisi ini. IAI sebagai organisasi profesi telah melakukan kegiatan sertifikasi Chartered Accountant (CA), Sertifikasi Akuntan Sektor Publik (SASP), Sertifikasi Akuntan Syairah (SAS), Sertifikasi Akuntan Pemerintahan (SAP). Profesi akuntan manajemen menyelenggarakan Certified Accountant Management (CMA), dan masih banyak lagi sertifikasi yang menjadi obyek kapitalisme. Hal ini belum kelihatan peruntukan dan prestige akuntan dengan keahlian yang beraneka ragam.

Chua (1986) menyatakan, riset akuntansi dikembangkan dengan mempertimbangkan aspek sosial yang disebut dengan riset akuntansi kualitatif yang terdiri dari paradigma positivisme, paradigma interpretif dan paradigma kritis. Sedangkan Burrel \& Morgan (1979) menyatakan ada empat paradigma yaitu; paradigma positivism, paradigma interpretif, radical humanist dan radical structural. Memasuki tahun 2000, perkembangan dunia akuntansi sudah mulai ada pergeseran yang dimulai dari riset akuntansi di Indonesia yang tidak berorientasi mainstream. Di Indonesia Riset akuntansi dikenal dengan multiparadigma yang dikenalkan oleh Triyuwono (2001) yaitu positivis, 
interpretivis, kritis, posmoderism dan spiritualis. Akhir Desember 2016 merupakan sejarah berdirinya Kompartemen Akuntan Syariah di Indonesia yang sudah disetujui oleh Ikatan Akuntan Indonesia. Kompartemen Akuntan Syariah (Aksyar) dirasa penting untuk diperjuangkan, karena mayoritas pemeluk muslim di Indonesia membutuhkan perjuangan etika dan muamalah yang sesuai dengan syariah Islam. Perjuangan akademisi IAI KAPd yang mempunyai kesamaan pandangan dalam akuntan syariah, yang diwadai dalam komunikasi Forum Dosen Akuntansi Syariah membuahkan hasil. Dalam kompartemen Aksyar ini terpilih sebagai Ketua Umum adalah Bpk Drs. Jusuf Wibisana., CPA yang juga anggota Dewan Standar Akuntansi Syariah Internasional/ AAIOSI. Harapannya keberadaan Kompartemen Akuntan Syariah ini akan membawa dunia pendidikan akuntansi Indonesia tidak harus berkiblat ke barat, tetapi lebih mengutamakan kondisi akuntansi berbasis Islam yaitu Al-Quran dan Hadist. Mulawarman (2016) Negeri ini milik kita bersama, umat Islam terdepan mengajak entitas umat lain membangun kebudayaan dalam kerangka religi bukan lainnya. Menjelang 2024 melakukan perubahan dengan mengedepankan kebudyaan, kebudayaan religiositas, kebudayaan bermarwah masjid.

\section{Tantangan Pendidikan Akuntansi Di Indonesia}

Visi ASEAN tahun 2020 bahwa, perkembangan sumber daya manusia di semua sektor ekonomi didukung oleh kualitas pendidikan, upgrade skills dan kemampuan serta training. Visi ini dapat dicapai dari pendidikan formal maupun informal yang bersertifikasi, serta penyelesaian kasus. Seperti yang telah di ungkapkan sebelumnya, adanya kesenjangan sumber daya manusia antara kebutuhan akuntan dan jumlah akuntan yang terdaftar serta jumlah lulusan mahasiswa akuntansi, menjadi perhatian dunia pendidikan akuntansi. Kesenjangan jumlah akuntan dan kebutuhan akuntan di Indonesia juga disertai kesenjangan kualitas akuntan. Kesenjangan jumlah akuntan antara akuntan yang dibutuhkan untuk memenuhi entitas dan jumlah akuntan yang ada di Indonesia belum terpenuhi, demikian juga kualitas akuntan masih lebih rendah dari akuntan asing. Kualitas akuntan dapat dilihat dari peningkatan kualitas auditor di Kantor Akuntan Publik. Kantor Akuntan Publik yang kecil, relatif kurang mengembangkan kemampuan profesionalisme sumber daya manusianya, dan kurang menjaga kualitas pekerjaan atau pengendalian kualitas audit. Sedangkan KAP the big four sangat memperhatikan kualitas audit dan selalu mengembangkan kemampuan profesionalisme nya, dan lebih mampu mengembangkan standar audit internasional maupun standar akuntansi internasional. Kondisi ini memunculkan persepsi negatif terhadap kualitas jasa akuntansi di Indonesia. Para pengguna laporan keuangan cenderung lebih percaya kepada KAP the big four.

Dunia pendidikan mempunyai tantangan dalam menyiapkan lulusan akuntansi yang mempunyai komitmen dan integritas secara profesional di bidang akuntansi, agar dapat bersaing dengan akuntan internasional. Pemerintah juga turut campur tangan dalam menangani akuntan, dengan dikeluarkannya Peraturan Menteri Keuangan PMK 
25/PMK.01/2014 tentang Akuntan Beregister Negara. Peraturan ini mengatur tentang regulasi terkait dengan registrasi ulang akuntan beregister, ujian sertifikasi akuntan profesional, kantor jasa akuntansi, pendidikan profesional berkelanjutan (PPL) untuk Akuntan, pengaturan akuntan asing dan organisasi profesi akuntan. Pemerintah juga bekerjasama dengan IAI Kompartemen Akuntan Pendidik dan IAPI serta IAMI menyiapkan peningkatan kualitas pendidikan akuntansi dan metode pembelajaran mahasiswa Strata 1 (S-1) dan Chartered Accountant (CA). Dewan Pengurus Nasional (DPN) IAI juga mempunyai kepedulian yang cukup besar terhadap perkembangan profesi akuntan di Indonesia, melakukan pembinaan terhadap perkembangan profesi akuntan yaitu Penataan profesionalisme akuntan melalui pendidikan akuntansi di Indonesia. IAI juga mengadakan workshop nasional dalam kurikulum akuntansi berstandar internasional, kurikulum akuntansi ini diharapkan dapat menghasilkan learning outcomes (LO) sesuai dengan yang diharapkan masyarakat, yaitu menghasilkan akuntan yang berkualitas dan profesional di bidangnya. Dalam International Education Standard (IES) No.3 tentang professional skills harus mempunyai skill di bidang intelektual, interpersonal and communications, personal dan organizational. Kurikulum yang dirancang di Program Studi Akuntansi harus disesuaikan dengan IES, dan Kerangka Kualifikasi Nasional Indonesia (KKNI) agar dapat menghasilkan kualitas lulusan yang lebih baik. Kurikulum yang ditentukan tersebut juga merupakan kurikulum barat yang seharusnya tidak sepenuhnya dipatuhi, tetapi perlu adanya keberanian sikap dari para akademisi untuk lebih mengedapankan keunggulan diri akuntan Indonesia.

\section{KESIMPULAN}

Posmodernisme menentang semua logosentris harmonization of accounting, yang merupakan hegemoni logosentris. Foucault telah melakukan pemberontakan terhadap hegemoni logosentris, yang mengesampingkan "sang lain/ the other", pada posisi marginal, terlupakan dan bahkan terhinakan. Artinya, ada bentuk-bentuk ilmu pengetahuan yang tertindas, demi menjaga wacana yang sedang berkuasa secara fungsional dan sistematis. Foucault menyatakan, pembebasan ilmu pengetahuan yang tertindas hanya dapat dilakukan melalui kritik, yaitu wacana yang menempatkan ilmu pengetahuan yang tidak ilmiah pada posisi sebagai wacana yang layak. Kritik ini oleh Foucault dinamakan "genealogi", yang mempunyai misi perjuangan melawan wacanawacana global dan universal yang saat ini menjadi kekuatan yang sedang berkuasa (Foucault 1980). Genealogi ini sebagai suatu proses sejarah yang tidak linear. Artinya, terbentuknya realitas sosial sebenarnya tidak melalui proses linier tetapi melalui proses yang polivalen dan "acak" yang menuntun kepada tujuan yang benar-benar belum diketahui secara pasti. Genealogi memberikan fleksibilitas dan kebebasan dalam melihat realitas sosial yang terbentuk dalam suatu masyarakat, yang berbeda dengan pandangan modernisme (positivism) Foucault (1987).

Ancaman tenaga kerja asing harus disikapi positif agar kita dapat mengembangkan kemampuan di bidang akuntansi dan auditing, serta perbaikan kurikulum akuntansi yang 
dapat meningkatkan kualitas pendidikan akuntansi di Indonesia. Pemberlakuan MEA di kawasan ASEAN juga dapat menjadi peluang bagi bangsa Indonesia untuk mengembangkan profesinya di ASEAN. Kesiapan pemerintah dan IAI serta profesi akuntan di Indonesia dalam menghadapi MEA ini mempunyai strategi yang matang dalam menghadapi liberalisasi akuntan di ASEAN. Kolonialisme Profesi Akuntan di wilayah ASEAN mempunyai dampak positif terhadap perkembangan akuntansi di Indonesia, perlu ada pembebasan/ liberalisasi, dalam melakukan pembinaan kualitas pekerjaan audit maupun penyiapan lulusan mahasiswa akuntansi di Indonesia. Kearifan lokal untuk menumbuhkan jiwa profesi Akuntan Indonesia perlu didukung oleh Pemerintah, sehingga tidak terjebak dengan kepentingan politik (political will) dan mencari keuntungan pribadi dalam proyek. Cengkeraman barat terhadap Indonesia sudah terlalu kuat, oleh karena itu perlu kekuatan profesi dan pemerintah untuk mengubah kekuasaan ini demi menjaga akuntan Indonesia.

Di Indonesia Riset akuntansi dikenal dengan multiparadigma yang dikenalkan oleh Triyuwono (2001) yaitu positivis, interpretivis, kritis, posmoderism dan spiritualis. Akhir Desember 2016 merupakan sejarah berdirinya Kompartemen Akuntan Syariah di Indonesia yang sudah disetujui oleh Ikatan Akuntan Indonesia. Kompartemen Akuntan Syariah (Aksyar) dirasa penting untuk diperjuangkan, karena mayoritas pemeluk muslim di Indonesia membutuhkan perjuangan etika dan muamalah yang sesuai dengan syariah Islam. Perjuangan akademisi IAI KAPd yang mempunyai kesamaan pandangan dalam Akuntan Syariah, yang diwadai dalam komunikasi Forum Dosen Akuntansi Syariah membuahkan hasil. Dalam kompartemen Aksyar ini terpilih sebagai Ketua Umum adalah Bpk Drs. Jusuf Wibisana., CPA yang juga anggota Dewan Standar Akuntansi Syariah Internasional/ AAIOSI. Harapannya keberadaan Kompartemen Akuntan Syariah ini akan membawa dunia pendidikan Akuntansi Indonesia tidak harus berkiblat ke Barat, tetapi lebih mengutamakan kondisi Akuntansi berbasis Islam yaitu Al-Quran dan Hadist. 


\section{DAFTAR PUSTAKA}

Burrell, Gibson and Gareth Morgan. (1979). Sociological Paradigms and Organisational Analysis: Elements of the Sociology of Corporate Life. London: Heinemann.

Chua, Wai Fong. (1988). Interpretive sociology and management accounting research-a critical review. Accounting, Auditing ang Accountability Journal 1 (2): 59-79.

Demyjazzy, (2011). Peran Akuntan dalam Pemberantas Korupsi di Indonesia. Oktober. Diakses dari http://demyjazzy.wordpress.com/2011/10/05/peran-akuntan-dalampemberantasn-korupsi-di-indonesia

Dewo., Setyo Anggoro., (2016). Workshop Nasional Kurikulum Akuntansi Berstandar Internasional. IAI. Dewan Standar Akuntan Profesional Nasional. Mei. Jakarta

Foucault, M. (1980). Power/Knowledge: Selected Interviews and Other Writings 1972-1977. New York: Pantheon Books.

(1987). Nietzsche, genealogy, history. In Michael T. Gibson (ed.). Interpreting Politics. Oxford: Basil Blackwell.

Gani, Lindawati., (2016). Workshop Nasional Kurikulum Akuntansi Berstandar Internasional. IAI. Dewan Pengurus Nasional. Mei. Jakarta

Hadiwinata, Bob Sugeng. (1994). "Theatrum Politicum": Posmodernisme dan Krisis Kapitalisme Dunia. Kalam. Edisi 1: 23-31.

Jitpaisanwattana, C., Pathumcharoenwattana, W., \& Tantawutho, V. (2015). The Analysis and Synthesis on Education Management for Readiness Preparation of Thai Workforce in Accounting for The ASEAN Community. Procedia - Social and Behavioral Sciences, 186, 944-949.

Koornhof C and Villier., (1999). Postmodernism and Accounting: Mirror or Myth?. Meditary Accountancy Research. Vol.7: 145-164.

Mulawarman., Aji Dedi. (2016). 2024 Hijrah Untuk Negeri. Kehancuran atau Kebangkitan Indonesia dalam ayunan peradaban. Yayasan Rumah Peneleh. Jakarta.

Triyuwono, I. (1996). Shari'ate accounting: an ethical construction of accounting knowledge. Critical Perspectives on Accounting Conference, New York,April 2628.

Upa, Vierly Ananta. (2015). Strategi profesi Akuntan Indonesia dalam menghadapi Liberalisasi jasa ASEAN. Jurnal GEMA AKTUALITA. Vol. 4. No.2 , Desember 2015. 37-45.

Wakhyudi. (2015). Kesiapan Sarjana Akuntansi Indonesia dalam Menghadapi 
Masyarakat Ekonomi ASEAN (MEA) 2015. 